\title{
A Neuroscientific Method for Assessing Effectiveness of Digital vs. Print Ads
}

\section{Using Biometric Techniques to Measure Cross-Media Ad Experience and Recall}

Ciceri, Andrea; Russo, Vincenzo; Songa, Giulia; Gabrielli, Giorgio; Clement, Jesper

\author{
Document Version \\ Accepted author manuscript \\ Published in: \\ Journal of Advertising Research \\ DOI: \\ 10.2501/JAR-2019-015 \\ Publication date: \\ 2020 \\ License \\ Unspecified
}

Citation for published version (APA):

Ciceri, A., Russo, V., Songa, G., Gabrielli, G., \& Clement, J. (2020). A Neuroscientific Method for Assessing Effectiveness of Digital vs. Print Ads: Using Biometric Techniques to Measure Cross-Media Ad Experience and Recall. Journal of Advertising Research, 60(1), 71-86. https://doi.org/10.2501/JAR-2019-015

Link to publication in CBS Research Portal

\section{General rights}

Copyright and moral rights for the publications made accessible in the public portal are retained by the authors and/or other copyright owners and it is a condition of accessing publications that users recognise and abide by the legal requirements associated with these rights.

\section{Take down policy}

If you believe that this document breaches copyright please contact us (research.lib@cbs.dk) providing details, and we will remove access to the work immediately and investigate your claim. 


\section{A Neuroscientific Method for Assessing Effectiveness of Digital vs. Print Ads: Using Biometric Techniques to Measure Cross-Media Ad Experience and Recall}

\section{Andrea Ciceri, Vincenzo Russo, Giulia Songa, Giorgio Gabrielli, and Jesper Clement}

Journal article (Accepted manuscript*)

\section{Please cite this article as:}

Ciceri, A., Russo, V., Songa, G., Gabrielli, G., \& Clement, J. (२०२०). A Neuroscientific Method for Assessing Effectiveness of Digital vs. Print Ads: Using Biometric Techniques to Measure CrossMedia Ad Experience and Recall. Journal of Advertising Research, 60(1), 71-86. https://doi.org/10.2501/JAR-2019-015

DOI: 10.2501/JAR-2019-015

Uploaded to CBS Research Portal in agreement with Journal of Advertising Research: http://www.journalofadvertisingresearch.com/

* This version of the article has been accepted for publication and undergone full peer review but has not been through the copyediting, typesetting, pagination and proofreading process, which may lead to differences between this version and the publisher's final version AKA Version of Record.

Uploaded to CBS Research Portal: May २०२० 


\title{
DIGITAL OR PRINT ADVERTISING? WHAT YOUR EYES AND YOUR BRAIN TELL ABOUT YOUR EXPERIENCE AND YOUR RECALL OF ADVERTISING IN DIFFERENT MEDIA
}

\begin{abstract}
Nowadays marketers can convey advertising on newspapers by means of several media, ranging from printed advertising presented via different paper formats to websites formats via internet. However, it is not clear, which medium is the most effective in terms of information memory or reading behavior.

This paper presents a study of advertisements in one newspaper presented for participants in three media formats; a) website format (via internet, using a desktop pc), b) paper format and c) digital format (a pdf version using a tablet device. Response to the very same news and advertising were measured using eye tracker, EEG brain scanner and memory test.
\end{abstract}

\section{MANAGEMENT IMPLICATIONS}

The newspapers' advertisings effect in three different media formats were compared in order to evaluate and characterize the specific medium in terms of memorization, visual attention and cognitive processing. Results showed that:

- The pdf digital version brings the highest memory performance, the greatest visual attention and at the same time the highest EEG frustration index (defined as a "state of perceived irritation") while watching advertising messages.

- The website has the lowest performance in terms of visual attention and memorization.

- The study provides relevant insights for marketers, on one hand related to the choice of medium and on the other benefits in practical use of neuroscience method.

Keywords: Eye Tracker, EEG, memory, advertising effectiveness, consumer psychology, neuromarketing, medium behavior. 


\section{INTRODUCTION}

Nowadays people are reached by advertising messages through different media and in the last decades media such as television and newspapers have been flanked by many new devices such as smartphones and tablets. These devices are now widespread and essential objects in everyday life, giving marketers many new sources to performing ads. However, it is not clear, which device is the most effective in conveying promotional information. Aside from traditional techniques such as memory recognition tasks, innovative psychological measurements are able to provide a broader evaluation of consumer's reactions to advertising. The study presented in this paper compares readers' reaction of three different types of media evaluated by their: i) advertising memorization, ii) visual attention and iii) cognitive response.

Three groups of participants read the same newspaper on three different media: $a$ ) website format shown on a desktop pc, $b$ ) paper format and $c$ ) digital format, which is a pdf version presented by means of a tablet.

The visual attention towards the advertisements in each medium format, was recorded by an eye tracker system synchronized with an EEG brain scanner. The advertising memorization was tested with a recognition tasks performed after the exposure to the advertisings. Results and conclusions are presented and advertising effectiveness related to readers' behavior is discussed comparing the three media formats.

\subsection{New types of media and new challenges for advertising}

Advertising is crucial for the success of services and products (Ademola, 2009) since it improves consumer's awareness (Mattila, 1999), it persuades the target to change their opinion or attitude enhancing a consumer's desire to purchase (Meyers-Levy and Malaviya, 1999), and it develops the competitive advantages of brand (Till and Busler, 1998).

In addition to communication strategy (Till and Baack, 2005; Baack et al., 2008), an important role in mediating advertising effectiveness is played by the chosen medium conveying the advertising message (Stafford et al., 2002). Each medium has typical features and thus elicits specific consumer behavior. Paper formats making use of the physical entity gives the reader an indication of the size and format. A digital version like a website is less tangible but allows readers to navigate through contents and to select the section to which they want to direct their attention.

Each medium facilitates different user behavior, by levels of engagement, level of attention and psychological attitude toward advertising. Decades ago, McLuhan (1964), stated that the psychosocial effect of medium on audience is higher than the message itself and that the medium affects advertisement effectiveness. Thus, it is important for a marketer to understand the relation between types of medium and advertising effects and how readers' behavior may change from medium to medium. This was in particular explored by Sundar et al., (1998) and Bezjian et al., (1998), who demonstrated that advertisements conveyed via paper formats are better retrieved and recognized than via internet.

An explanation for this difference was explained for the first time by Benway and Lane (1998) as "banner blindness", which refers to the tendency of users to avoid looking at banners when viewing websites. Banners and "skyscrapers ads" (vertical banners) compete with surrounding editorial contents in terms of visual attention (Drèze and Zufryden, 2000). In an eye movement study on Internet search (Drèze and Hussherr, 2003), it was found that people were able to spot banner ads positioned in peripheral areas of visual scenes, and intentionally avoid them. In addition, only $46.9 \%$ of subjects remembered seeing any banner ads during the test. Moreover, a recognition task revealed that subjects were not able to distinguish accurately ads that were presented during the experiments from ones that had never appeared. Lapa (2007) observed that when having the same structure/design of websites, the duration of eye fixations on the banner decreased progressively for each page viewed. This is probably due to human learning processes enabling subjects to adapt fast to visual stimuli and 
in this case to avoid advertising banners. Another study carried out by Hervet and colleagues (2011) found that $63.3 \%$ of website banners were not fixated, while Lohse (1997) demonstrated that on a printed support (i.e. Yellow Pages) the percentage of advertisements not viewed was only 10\%. Recent studies by Simola et al. (2013) showed similar results about how banners are less viewed when users are reading text on webpages, and a review article by Higgins et al. (2014) supports the claim, that advertising via Internet is affected by ad avoidance in terms of visual behavior.

Although there are several researches about Internet and paper advertising, there are limited published research on how people divide their visual attention when using a tablet, and even less research about the effectiveness of advertising presented in this medium. Yet, in some studies from marketing companies, it has been found, that users of this digital device have a more positive attitude towards advertisements. Probably because they consider advertisements as an acceptable part of the contents when news is brought to them by means of a tablet (Sentinel, 2012).

In order to provide a scientific contribution to this field of research, the present study deepens research results from previous scientific studies (Bezjian et al., 1998; Sundar et al., 1998) adopting neuromarketing approach to compare newspaper advertising effects via website, paper and digital formats (on tablet). Also, in continuation of previous studies (Tewksbury and Althaus, 2000; Eveland and Dunwoody, 2001), a paper format of the very same newspaper was embedded in the study, in order to be compared with the online website version.

The digital version was assessed by means of a desktop computer and a pdf digital version of the newspaper shown on a tablet device. The tablet was used with the aim to respect the ecological validity, as $95 \%$ percent of Italians e-readers read the digital version of their newspaper via a tablet. The last 5\% read the newspaper as pdf version on their pc (www.audiweb.it).

\subsection{Measuring people's response to advertising}

Asking what subjects think, feel or usually do have been well proven methods for testing consumer behavior in psychology. However, these methods do also have their drawbacks due to the well-known limited self-awareness (Pryor, et al., 1977), or the social-desirability phenomenon (Arnold and Feldman, 1981). Subjects report what they think is "the right answer" or what is socially acceptable to say, which challenge the objectivity in measuring reactions to affective context such as advertising. As Poels and Dewitte (2006) explain it, through neuromarketing tools it is possible to capture the effects of an advertisement and the feelings that it provokes. Poels and Dewitte (2006) further conclude, that in relation to advertisements the physiological measures have higher predictive power than self-reports.

In the last few decades, several studies have explored these kinds of neuroscientific applications in the fields of communication and consumer behavior (Ohme et al., 2009; Plassmann et al., 2012; Khushaba et al., 2013), and the field of research named neuromarketing, has achieved growing interest (Lee et al., 2006). Neuromarketing is a branch of marketing that utilize neuro and biometric technologies, to assess consumers' affective reactions (Lang., 1995; Larsen et al., 2003; Rainville et al., 2006). Neuromarketing has already been applied to advertising messages (Missaglia et al., 2017), packaging (Liao et al., 2015), brands (Venkatraman et al., 2012) or other stimuli and consumer experiences (Ciceri et al., 2015; Mauri et al., 2012; Russo, 2015).

The ability to record physiological reactions to different stimuli or media has open a way to a wider understanding of consumer behavior and for this reason, this study measures the effects of advertising conveyed on different media, not only in terms of using recognition tasks, but also in terms of visual attention and cognitive response through biometric techniques such as eye tracking and EEG. 


\subsection{Memorizing advertising and its relation to visual attention}

The memory process represents a key factor in marketing because it is a critical part of how advertising influences consumer behavior (Mehta and Purvis, 2006). According to the scientific literature, consumers' brand evaluation and purchase decisions are affected by the remembering of an advertising campaign because people do not buy a product during or right after advertising exposure (Alba, et al., 1991; Nedungadi et al., 1993). Owing to this reason, memorization of advertising is a typical measure of effectiveness, with a number of empirical studies demonstrating its worthiness (Dubow, 1994; Lodish et al., 1995).

Memorization measures widely used in advertising research are 'recognition' and 'recall' tests, used in cued memory tasks (Friestad and Thorson, 1993; Kellaris et al., 1993). Recognition is a memory technique involving consumers being asked to choose which advertisements they have been exposed to, among a list of advertisements that have and have not been showed during a previous experimental test. Conversely, free recall assessment provides a trustworthy simulation to evaluate consumers' ability in remembering an advertisement. However, it only relies on the participant's memory, without a list of stimuli (Bettman, 1979).

Recognition is a more effective measure of memorization than recall (Krugman, 1972), because the latter may mask the amount of actual memory (Zielske, 1982). The recognition score is the proportion or percentage of the recognized stimuli in relation to the whole number of advertisements and it has been used in a large number of studies about advertising memorization (Perfect and Askew, 1994; Du Plessis, 1994; Furnham and Mainaud, 2011; Simola et al., 2013). For instance, Perfect and Askew (1994) compared the percentage of recognized ads between a deliberate and an incidental advertising exposure in a color magazine. Simola and colleagues (2013) used a recognition task to demonstrate that congruency between ads and editorial texts improves memory for advertisements.

The relation between cognitive processing such as memorizing and eye movements has been found for picture stimuli (Christianson et al., 1991; Loftus 1972), print advertisements (Pieters et al., 1999; Rosbergen et al., 1997; Krugman et al., 1994) and television commercials (Thorson and Zaho, 1997). Rayner (1998) labeled it as the "Eye Mind hypothesis", as the human visual system has been found to have a strong relation with higher-order cognitive processes (Russo, 1978; Rizzolatti et al., 1994) and by that related to brand memory and decision-making.

Measuring visual attention is essential when examining the effectiveness of advertisements because, eye movements have a strong relation with higher-order cognitive processes (Russo, 1978; Rizzolatti et al., 1994).it is related to brand memory (Wedel and Pieters, 2000), consumers' attitudes (Rosbergen et al., 1997) and decision-making (Pieters and Warlop, 1999; Chandon, 2002). Visual attention is conceptualized as "a brain operation producing a localized priority in information processing - an attentional 'window' or 'spotlight' that locally improves the speed and reduces the threshold for processing events" (Deubel and Schneider, 1993).

In recent years, thanks to technological progress, visual attention has become available to assess through eye tracking system, a technology that enables to detect and analyze the visual attention focus and its amount (Laubrock et al., 2007). O'Connell et al. (2011) reported a study that confirms the usefulness of eye tracking, stating that it provides more accurate information than self-reports or memory scores.

In terms of memorization, several studies demonstrated the relation between visual attention and brand memory (Chandon, 2002; Wedel and Pieters, 2000; Pieters and Warlop, 1999; Rosbergen et al., 1997). In particular, these studies have shown, that an increase in eye fixations on an item increases the likelihood of remembering it. The longer and deeper the visual attention to advertising is, the stronger the extent to which users can actually learn from it and to which they will recognize and recall it (Mehta and Purvis, 2006). O'Connell et al. (2011) even reported a study confirming the benefit of eye tracking, stating that it provides more accurate information than self-reports or memory scores. 


\subsection{Brain response to advertising}

Irritation in advertising is the factor considered in this research because this emotional state is an important predictor of advertising effectiveness reducing short-range and, particularly long-range effectiveness (Greyser, 1973) as well as persuasion (Aaker and Stayman 1990; Duncan and Nelson 1985). In fact, some advertising practitioners say that irritation and effectiveness walk hand-in-hand. There are several researches that have studied the effect of advertising in terms of irritation (Gallagher et al., 2001; Fennis and Bakker 2001; Aaker and Bruzzone, 1985; Wells et al., 1971), annoyance (Mccoy, et al., 2007; Nagar, 2009), disturbance (Reed, 1999), avoidance (Speck and Elliot 1997) or skepticism (Obermiller and Spangenberg 1998) rather than engagement.

Rothschild (1982) founded a modest but significant correlation between the number who used the word irritating to describe the commercial and the overall level of brainwave activity (EEG) while viewing the commercials.

Even today, with the development of information-processing technology that allows advertisers to shift the orientation of their efforts from traditional mass advertising to tailored advertising to deliver messages personalized on the basis of subjective preferences, advertisements are still considered to be unwelcome and annoying. For this reason, consumers often use various advertisement avoidance tools, such as blocking online advertisements and when these tools are not available, they simple avoid paying attention to the advertisement itself (Baek and Morimoto, 2012).

For these reasons the authors choose to consider the irritation factor as an indicator of emotional involvement generated by the vision of the same advertisements on the three media considered.

As the irritation factor is the emotional state that typically characterizes advertising, especially nowadays with a greater advertising pressure, the authors believe that it is also more indicated to better connotate and differentiate the emotional reaction to the advertising on the three media.

In recent years, researchers have attempted to investigate brain activity during the viewing of commercial advertisements (Langleben et al., 2009; Vecchiato et al., 2010; Dmochowski et al., 2014; Barnett and Cerf, 2017). This interest is justified by the possibility of identifying indirect variables of emotional and cognitive processing, by recording variations in the activity of specific brain structures linked to human reactions (Vecchiato et al., 2014).

A widely used method to detect brain activity is the ElectroEncephaloGraphy (EEG). This technique measures the cortical activation of the subjects by means of electrodes placed along the surface of the scalp. A high temporal resolution enables the EEG to detect brain activity associated to changing stimuli (Vecchiato et al., 2014; Ohme et al., 2009). The benefit in using EEG for testing television commercial was demonstrated by Deitz et al. (2016), providing a continuous record of arousal data directly related to a specific stimulus.

\section{METHOD}

\subsection{Experimental technologies}

Eye movement recording - Eye movements were recorded using the VideoOculoGraphic technique (VOG). VOG uses an image of the eye taken by a digital video camera to compute gaze position. In order to make this data processing fast enough to be performed in real time, the eye is illuminated with infrared light to create corneal reflexes. Being invisible to the subject, the infrared light does not create a distraction.

For the experiment described in this paper, two eye tracking recording devices were used. SMI RED250 (see Figure 1), a remote system (sampling frequency $250 \mathrm{~Hz}$ ), and SMI eye tracking Glasses (sampling frequency $60 \mathrm{~Hz}$ ), which is a wearable device (see Figure 2). Data from the remote system was resampled at $60 \mathrm{~Hz}$ in order to be compared with data from the eye tracking glasses. SMI 
technology and its software "Be Gaze" have already been used in several scientific papers (Simola et al., 2013; Cowen et al., 2004; Humphrey and Underwood 2009; Kessels and Ruiter 2012).

EEG recording - ElectroEncephaloGraphic activity has been recorded by means of the Emotive EPOC headset (www.emotiv.com). This device (see Figure 3) is comprised of 14 EEG channels located at the positions AF3, F7, F3, FC5, T7, P7, O1, O2, P8, T8, FC6, F4, F8, and AF4 according to the International 10-20 system (Cacioppo et al., 2000). The Emotive EPOC headset samples at a frequency of $2048 \mathrm{~Hz}$, which then gets down-sampled to $128 \mathrm{~Hz}$ sampling frequency per channel. The data are sent to a computer via Bluetooth using a proprietary USB dongle to communicate using the $2.4 \mathrm{GHz}$ band. As other proprietary algorithm like the one from Sands Research (Deitz et al., 2016), the reliability of the EPOC headset (Esfahani and Sundararajan, 2011) and its algorithm, Affective Suite, has been demonstrated in a number of recent publications (Grant and Schmidt, 2012; Lievesley et al., 2011; Goldberg et al., 2011; Gonzales-Sanchez et al., 2011; Kuber and Wright, 2013; Khushaba et al., 2013; Ohme et al., 2009).

All of the technologies were synchronized by means of the Observer XT from Noldus (www.noldus.com).

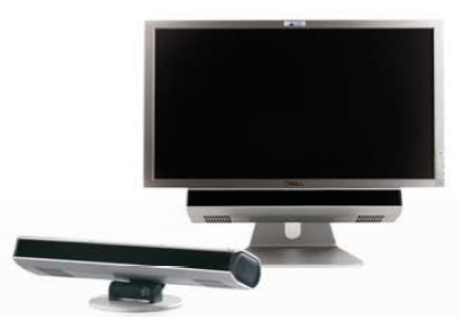

Figure 1 - SMI RED250 VOG recording systems

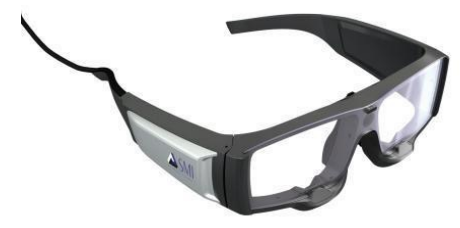

Figure 2- SMI RED250 VOG recording systems

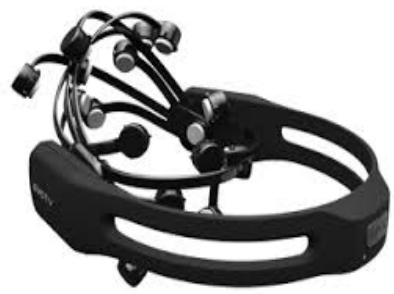

Figure 3 - EEG Epoc Emotiv headset

\subsection{Experimental protocol}

A national Italian newspaper was used for the study, provided via three media: a website news exposed through a PC laptop, a printed edition (paper), and a digital edition (pdf file) viewed via tablet. Twenty-five real and static advertisements appeared in the three media, presented in each medium in the same order. The advertisements were identical in the three media and had the same size (in proportion compared to the page size). Figure 4 shows an example of the advertising images.

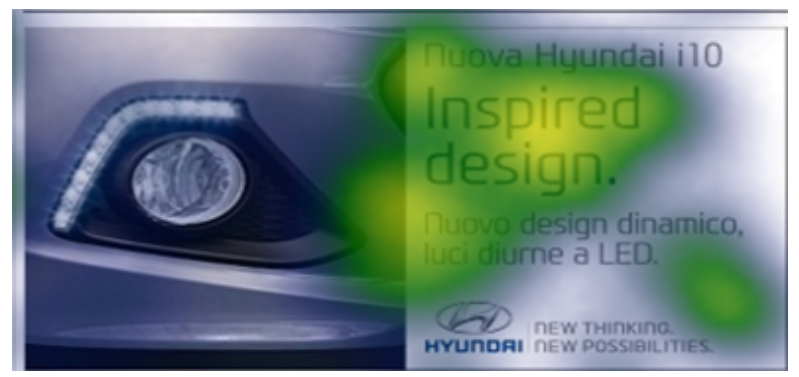

Figure 4 - An example of advertising.

For the study, a mock newspaper was created for each medium that in all aspects was identical to the original version of the newspaper to ensure a genuine comparison among the media. A total sample of 72 habitual newspaper readers ( 36 males) aged between 23 and 55 years (mean $=38 \pm 9.15$ years) participated in the research study. The authors have selected this target group, because it is 
representative of Italian newspaper readers (Auditel.it). A stratified sampling method has been used, considering gender, age and randomization as crucial.

All the subjects were healthy, right-handed subjects with no personal or family history of mental illness. We controlled this variable considering the hemispheric lateralization theory, even if its validity has been criticized at least in advertising field (Katz, 1983).

Participants were divided into three subgroups of 24 participants to ensure an equal distribution between gender and age. Each group of subjects only read the newspaper on one of the three media (here called condition 1,2,3). Table 1 shows the distribution of participants across sex and age range for each group.

\begin{tabular}{lll}
\hline & \multicolumn{2}{l}{ Subjects Age range } \\
\cline { 2 - 3 } & $28-39$ & $40-55$ \\
\hline Males & 6 & 6 \\
Females & 6 & 6 \\
\hline
\end{tabular}

Table 1 - Participants for each subgroup

The room where the participants read the newspaper was quiet and brightly illuminated with the same lighting condition. The display's luminance of the two technological devices was the same and was set so that reading on the web page and the tablet was perceived as comfortable.

Condition 1 (Website format): after the Epoc Emotiv EEG headset has been adjusted to the testperson it was synchronized with the system. Then the subject was seated $60 \mathrm{~cm}$ away from the computer screen, which had embedded the SMI-RED250 eye movement recording system. Before starting the eye movements' recordings, a 5-point calibration was carried out using SMI iViewX software. The monitor used to display the newspaper was a Dell $17.3 \mathrm{inch}$, set with the same screen brightness of the tablet.

Condition 2 (Paper format): after the EEG headset and SMI eye tracking Glasses have been adjusted to the test-person, the subject sat in front of a book holder with the traditional version of the newspaper (printed-paper). The use of the book holder allowed us to control for the visual angle display, as it was placed at the same distance from the seat where the subjects was placed $(60 \mathrm{~cm})$. Eye tracking calibration was performed by asking the subject to fixate five points indicated by the experimenter on the paper surface.

Condition 3 (Tablet format): after the EEG headset has been adjusted to the test-person, the subject sat in front of a book holder carrying the tablet. The tablet (9.7-inch screen) displayed the digital edition of the newspaper in pdf format. All the subjects were placed at the distance of $50 \mathrm{~cm}$ from the seat, and they used the same tablet set with the same screen brightness of the monitor used to show the website, wearing SMI eye tracking Glasses. Eye tracking calibration was performed by asking the subject to fixate on five points indicated by the experimenter on the tablet surface.

In all the three conditions the subjects were asked to read the newspaper freely at their own pace. The only condition was the impossibility of going back to read a news. They could only move forward. The same 25 advertisements were exposed in the same order for each of the three media. Each experimental condition ended automatically when all 25 advertisements have been shown on the medium.

Distraction task: after reading the newspapers on the different media, participants did a distraction task, lasting about one hour, after which the memory recognition task followed.

Memory recognition task: a typical recognition task was carried out after test-persons have been exposed to the advertisements. The recognition task was made on computer screen, where each 
subject was exposed to 50 advertisements for 6 seconds - half of these advertisements were distractors and the other 25 were the same advertisings showed during the reading of newspaper.

Participants rated their responses clicking with the mouse a "yes" to indicate that they had previously seen the advertisement or "not" option if they had not, with both response points appearing on the same PC screen.

\subsection{Data analysis}

Eye movements' analysis was performed offline using BeGaze software. On each advertisement an area of interest (AOI) has been defined and software calculated several parameters for each AOI. Specifically, in this study the average gaze duration or in other term average fixation time was analyzed from the first entry of the eyes into the AOI. This eye movement measure represents the duration of every fixation on each advertising image, which is the total time spent viewing each advertisement.

Because vision is effectively suppressed during saccades (Henderson and Hollingworth, 2003), they have been excluded from the analysis. Therefore, eye movements lasting less than 40 milliseconds have been filtered and excluded from the analysis (Rayner, 1998). Fixations lasting less than 110 msec and greater than $2350 \mathrm{msec}$ were eliminated as outliers.

As measure of visual attention on advertising the authors therefore opt for fixation time, because its validity as an indicator of visual attention has been empirically demonstrated (Christianson et al. 1991). Fixation time is a measure largely used in the research on attention and advertising memorization (Rosbergen, et al., 1997; Henderson and Hollingworth, 2003; Ares, et al., 2013).

In the analysis, number of fixations has not been considered as visual attention measure, because this index has the limit to consider in the same way fixations with different durations (Tatler et al., 2005). Fixation time was also used as it represents the duration during which information acquisition and processing for a particular advertising element can occur (Scott et al., 2015).

EEG analysis is provided by Emotive Affective Suite, a software package that reports real time changes in subjective emotions experienced by the user. Emotiv Affective suite offers five distinct affective detections: Engagement (a reflection of the alertness and conscious direction of the attention towards task-relevant stimuli) - Excitement Long Term and Excitement Short Term (which describe an experience of awareness or positive physiological arousal) - Frustration (representative of an irritation state) and Meditation (which indicates a type of relaxed state) (Inventado et al., 2010; Goldberg et al., 2011; Koutepova et al., 2010).

The frustration affective index was used in this study. As described in a previous section, it is mostly related with the typical state of perceived irritation caused by advertisements. It could be defined as "consumers' perceptions of the extent to which advertising is causing displeasure and momentary impatience" when they are reading a digital (Mccoy, 2007) or traditional newspaper or seeing a television program and an advertising appears (Aaker and Bruzzone, 1985).

In this study, the EEG affective detection was registered continuously during the entire experiment.

The eye tracker and EEG were synchronized in order to be able to isolate and therefore analyze specifically the EEG data during the observation of advertisements.

Detecting and removing artifacts in the EEG data due to muscle activity, eye blinks, electrical noise, is an important issue in EEG signal processing analysis. Already the Epoc Emotiv hardware applies independently band-pass filters in order to remove the 50 and $60 \mathrm{~Hz}$ power components and other forms of preprocessing to reduce noise. Moreover, data about EEG frustration index was carefully inspected to detect artifacts/changes due to head movements or any other kind of signal noises.

We used a combination of Independent Component Analysis (ICA) (Hyvarinen, et al., 2001) and a semi-automated rejection coupled with visual inspection, using the EEGLAB software for artifact rejection. Outliers were removed using $R$ software and Matlab. Only the EEG data recorded during the participants' eye fixations of static advertisings was considered for the analysis. After this 
preliminary EEG data selecting and cleaning phase, it was possible to assess cerebral response during advertisement visualization for each medium.

\section{RESULTS}

\subsection{Eye Tracking results}

The eye-tracking data did not follow a normal distribution (Shapiro-Wilk test $p$-value $<.05$ ), thus nonparametric analyses were performed.

Firstly, it was assessed whether the number of pages read had an effect on readers' experience. Therefore, the average fixation time on ads in the first pages was compared with the average fixation time on ads in the last pages. Results revealed that there was not a significant difference (MannWhitney test, $p$-value $>.05$ ). Thus, the number of pages read or browsed did not affect participants' visual behavior.

Thus, analyzing the average fixation time spent on advertisements, the value was the lowest for the website medium compared with both the tablet and paper media. The highest value was observed with the tablet medium (Table 2).

\begin{tabular}{ll}
\hline & Fixation time $(\mathrm{ms})$ \\
\hline Web & $553.26 \pm 904.67$ \\
Paper & $1364.97 \pm 1379.96$ \\
Tablet & $1879.32 \pm 1173.74$ \\
\hline
\end{tabular}

Table $2-$ Median \pm standard deviation of the fixation time index during the ads visualization in web, paper and tablet media.

Statistical analysis showed that there was a significant difference in the fixation time on the advertisements among the three media (KruskallWallis $p$-value $<.05$ ). Post-hoc Nemenyi test revealed that the difference is significant between web and paper and between web and tablet (see Figure 5).

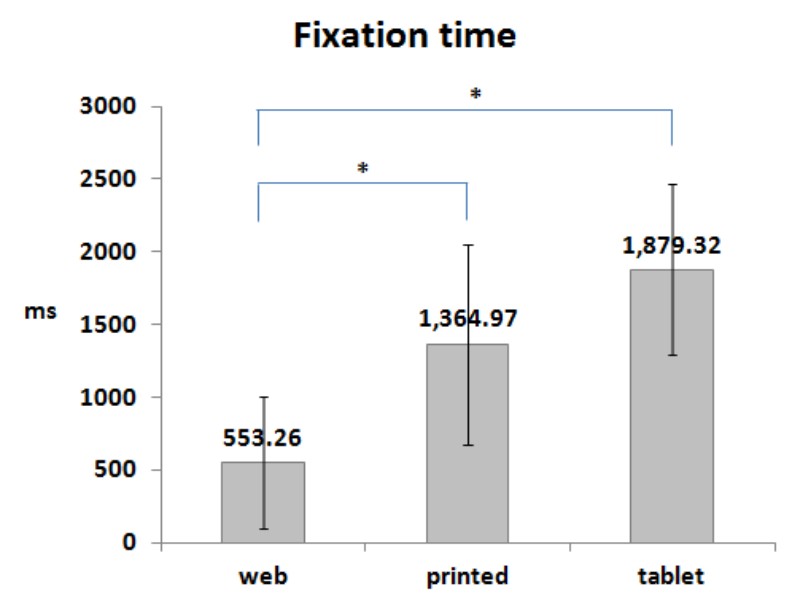

Figure 5-Mean values for fixation time on advertisings, differences between tablet and web and between paper and web are statistically significant $(p<0.05)$. 


\subsection{Memory Performance results}

An index of memory performance relying on the results of the recognition task was computed. The index is the mean of two different indexes: the proportion of correct recognition (answer "yes" to a target advertising) on the whole number of advertisings (25) and proportion of "true negative" (answer "no" to a distracters) on the whole number of distractors (25).

The data were normally distributed, thus parametric tests were used to perform the analyses. The subjects who used the web medium had the lowest value in the memory performance index, while the higher value was achieved by participants who used the Tablet medium (Table 3 ).

\begin{tabular}{lc}
\hline & Memory performance index \\
\hline Web & $0.66 \pm 0.133$ \\
Paper & $0.72 \pm 0.099$ \\
Tablet & $0.74 \pm 0.098$ \\
\hline
\end{tabular}

Table 3 -participants Mean \pm standard deviation of the memory performance index in web, paper and tablet media conditions.

Anova analysis revealed significant differences in the memory performance among the three media: $\mathrm{F}(1,69)=5.98 ; \mathrm{p}$-value $<.05$. Post-hoc Tukey test revealed that the difference was significant between Web and Tablet (see Figure 6).

Memory performance

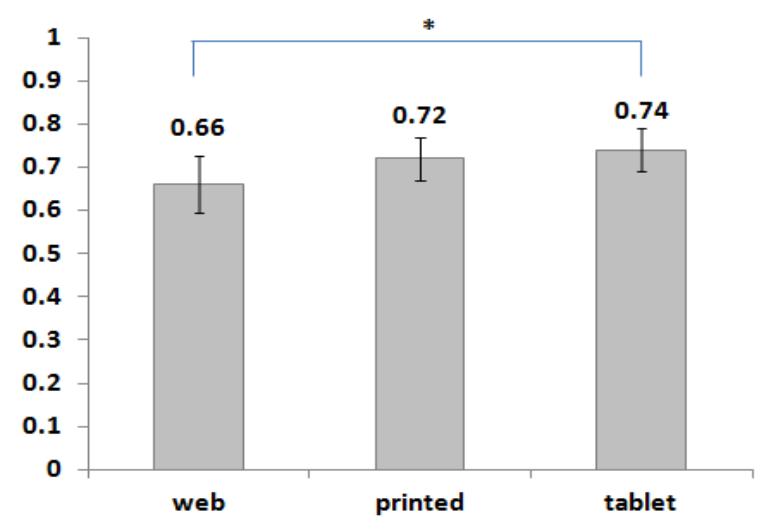

Figure 6-Mean values for Memory Performance index, differences between tablet and web are statistically significant.

\subsection{EEG results}

EEG data for each subject during each advertisement exposure was analyzed. As first reported, authors chose the frustration EEG index as a measure of the perceived irritation when looking at an advertisement. EEG frustration is more in general an index inversely related to the level of pleasure. An EEG frustration value closer to zero indicates a condition of perceived pleasantness while a number closer to maximum value (1) reflects unpleasantness situation. 
The EEG data did not follow a normal distribution (Shapiro-Wilk test p-value $<.05$ ), thus nonparametric analyses were performed. Even for this index, it was assessed whether the number of pages $\mathrm{read} /$ browsed had an effect on readers' experience, adopting the same comparison done for eye tracking data. To do that, the average EEG frustration index in the first pages was compared with the average EEG frustration index in the last pages. Results revealed that there was not a significant difference (Mann-Whitney test, $p$-value $>.05$ ). Thus, the number of pages read or browsed did not affect participants' response in terms of EEG frustration level. The median and standard deviation of this index during the visualization of each advertisement was computed (Table 4).

\begin{tabular}{ll}
\hline & EEG index \\
\hline Web & $0.413 \pm 0.144$ \\
Paper & $0.577 \pm 0.158$ \\
Tablet & $0.599 \pm 0.376$ \\
\hline
\end{tabular}

Table 4-Median \pm standard deviation of the EEG frustration index during the advertisements visualization in web, paper and tablet media.

As reported in Table 4 and Figure 7, the EEG frustration index during the visualization of the advertisements in the web medium is the lowest value, while during tablet advertising exposures the values are the highest on average. In the paper condition, the value is closer to Tablet in comparison to web conditions. Statistical analysis revealed significant differences in the EEG frustration index among the three media (Kruskal-Wallis chi-squared p-value $<.01$ ). Post-hoc Nemenyi test revealed that the difference was significant between tablet and web on one side; paper and web on the other side, and finally between tablet and paper conditions during the advertising exposure (see Figure 7).

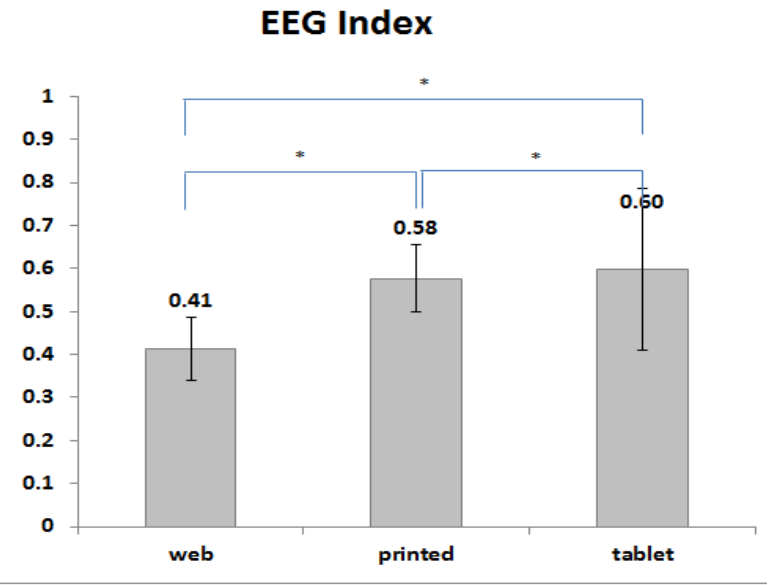

Figure 7 - Median values for the EEG frustration index. Differences between each couple of medium are statistically significant.

\section{DISCUSSION}

Results showed a significant difference among the three media for all of the considered measures. Specifically, as shown in Table 5, the only medium that resulted in significant differences for all metrics (Memory Performance, eye tracking data and EEG frustration Index) is the web compared 
with the tablet. The results for the web compared with paper medium shows two metrics with significant differences: eye-tracking data and EEG frustration index. No significant difference emerged between print and web media in terms of memorization performance. As other researches have shown (Gallagher et al., 2001), both media are equally effective considering this metric. When comparing tablet and paper conditions, significant differences did not emerge with the only exception of the EEG frustration Index data.

These findings confirm a well-defined and very typical behavior about advertising experienced on different media as already demonstrated in other studies (Varan et al., 2013). In particular, a similar behavior reaction to advertising conveyed via tablet and paper has been found. Web is instead characterized by a typical and very different reaction to advertisings stimuli. These differences related to advertising performance could be due to different reading behaviors that characterize each medium. On one side, results from tablet and paper media are very similar. On the other side, web conditions represent a medium characterized by a very different behavior reflected by results here reported. Media experts have reported, that digital version of newspaper read via tablet or other mobile devices will replace the printed-paper (Anderson et al., 2012). Yet some nuances have to be taking in consideration, as data collected in this study, indicates that reading behavior might be closer to a classical newspaper reader for tablet readers than for readers making use of websites.

\begin{tabular}{llll}
\hline & $\begin{array}{l}\text { Memory } \\
\text { Performance } \\
\text { results }\end{array}$ & $\begin{array}{l}\text { Eye- } \\
\text { tracking } \\
\text { results }\end{array}$ & $\begin{array}{l}\text { EEG } \\
\text { results }\end{array}$ \\
\hline Web vs Tablet & $\mathrm{p}<.05$ & $\mathrm{p}<.01$ & $\mathrm{p}<.05$ \\
Web vs Paper & Not Sign. & $\mathrm{p}<.05$ & $\mathrm{p}<.01$ \\
Tablet vs paper & Not Sign. & Not Sign. & $\mathrm{p}<.01$ \\
\hline
\end{tabular}

Table 5 - Summary about all significant differences amongst the metrics considered.

Focusing on visual attention data, total fixation time was higher for tablet and paper media in comparison to the web medium. Participants spent less time watching advertisements, thus remembering fewer of the advertisements, when they were reading the newspaper via website. This result is consistent with previous studies that explained this phenomenon as banner blindness. While the structure of the website leads to a quick learning of the position of the advertising (Lapa, 2007), this is not the case for printed (Lohse, 1997) or tablet medium.

Another explanation for this result could be related to receiver's expectations of the appropriateness of advertising in the online medium. When readers are interactive in their use of online medium and perceive the medium as a channel for news and information, they might consider it inappropriate for advertising (Sundar et al., 1998). In fact, Brackett and Carr (2001) reported that advertising via internet is perceived as irritating, and for this reason e-readers avoid looking at the ads.

As for visual attention, the same trend is found for the EEG data. A higher value in the EEG frustration Index, related to an increased activity of brain waves associated with consumers' perceptions of irritation and displeasure, which is generated when people were watching advertising via tablet and paper, while the lowest value is elicited with exposure to advertising via internet by means of a website.

Explaining all these findings in terms of behavioral responses, participants are not only less prone to spend time (in terms of visual attention) on advertising stimuli when they are reading the newspaper 
via a website, but they also experience the lowest EEG frustration. Considering the results based on recognition task, the memory performances are also the highest for subjects viewing advertisements via tablet and paper media, and lowest when viewing them via website. These results, once again, support the banner blindness hypothesis.

The poor performance of the web medium in terms of advertising memorization may also be supported by several previous studies in mass communication that have examined differences in learning from the web compared to traditional print medium (Eveland and Dunwoody, 2001; Tewksbury and Althaus, 2000). Several studies have found that consumer attitudes toward print advertising are in general more positive than their attitudes toward advertising on web (Ha and McCann, 2008; Grussell, 2007).

Scientific research found that advertising on printed newspaper is considered by readers to be informative and useful as the editorial content itself. Readers perceive newspapers' advertising less annoying than advertising in other interactive mediums compared to internet (Elliott and Speck, 1998). This aspect has been confirmed in this study with the eye tracking data. On average, readers spent more time looking at the advertisings conveyed via paper and tablet thus denoting a minor annoyance effect of advertising in these media. The same has not been confirmed with the EEG frustration index, that in the printed and tablet newspaper was higher than in the website condition denoting more irritation. This could be explained by the minor amount of attention that readers on average spent on advertising conveyed via website, which may have elicited a consequent smaller amount of irritation and annoyance as reflected in the EEG frustration Index.

The unpleasant experience proved by readers when they saw advertisings on printed newspaper and tablet seems not having a negative effect on ad memorization that was higher in comparison to the same indicator for the website newspaper (medium in which the EEG frustration amount was minor). As already known, in adverting even a very unpleasant ad could be effective as a very pleasant one (Greyser, 1973) as strong negative or positive emotion are more effective than those in between. In this study, negative emotions combined with higher amount of attention on advertising contributed positively on advertising memorization.

Taking together, the results confirm the role of the medium as an important variable to take in consideration for evaluating the effectiveness of the communication between senders and receivers (McLuhan, 1964) and for assessing advertising. The combination of eye tracking and EEG data has been shown to be methodologically feasible and represents a potential means enabling to gain new insights into the neurocognitive and behavioral bases of reading in general (Dimigen et al., 2011) and in particular with this study, of advertising effectiveness during news reading.

\section{CONCLUSIONS}

The results show how evaluation of advertising effectiveness in terms of memorization, visual attention and cognitive processing is influenced by medium type. Moreover, the banner blindness hypothesis has received additional support from data presented and analyzed in this research and by means of neuromarketing techniques. On one hand eye tracking data shows that people spend more time on advertising flyers when reading a newspaper via tablet and via paper in comparison to website navigation. On other hand brain waves associated with a perceived unpleasantness showed greater activation, during viewing advertisements when reading a newspaper via tablet and paper rather than via internet by means of a website. It underlines the benefits in applying new techniques such as eye tracking and EEG in combination with "pen-and-paper" techniques, such as memory tasks performance. This multi-method approach to a marketing issue provides a deeper understanding of reader behavior and enhances the possibility to describe consumer's psychological and behavioral response to advertising.

Other disciplines might take advantage of this multidimensional approach, enabling to go further and develop more complete and broader ways to measure consumer behavior by the merging of 
neuroscientific methods in the field of marketing on one side, and exploring and evaluating how it is possible to improve the scientific methods in the field of communications sciences on the other side. The study gives marketers and academics a here and now picture of consumer reactions towards advertising on different media as they appear on the market today. Compared to others, the research we conducted offered the opportunity to compare 3 different media. Other published research with similar approaches often considered only one medium at time (Rothschild, 1988; Deitz et al., 2016; Venkatraman, 2015; Ambler, 2000; Orzan, 2012; Daugherty, 2012; Varan, 2013; Wawrzyniak and Wasikowska, 2016).

Looking in particular at the study of advertising effectiveness in newspapers, no researches have been conducted using the neuromarketing approach.

In today's context characterized by multi-channel advertising, to know the typical features of each newspaper medium is strategic to plan an effective media mix able to optimize consumer attention, engagement and advertising memorization on newspapers. This research demonstrated that nowadays marketers can measure attention and therefore understand the possibility that the advertisements have to be noticed. In addition, measuring EEG activation, they are able to have access on the nonconscious effect of advertising on consumers. And what is more important they are able to have a more detailed view on the mediums' typicality.

\section{LIMITATIONS AND FUTURE DIRECTIONS}

It is important to underline that in additional to the significant results presented in this paper, there are some critical points that should be taken into account. Firstly, when conveying the results of this study to marketers and professionals, the priority of ecological validity over methodological issues should be highlighted. The decision to compare results from different media with different experimental protocols preserving the typical ways of usage has the gain of taking advantage of natural and most common conditions about newspapers' exposure in real daily life within the lab experimental conditions. However, the use of different experimental protocols leads to the possibility that external variables might affect the results, even where previous research has used the same experimental setup (Tewksbury and Althaus, 2000; Eveland and Dunwoody, 2001).

In order to decrease the effects of external variables as much as possible, the same stimuli (advertising images) were shown in the three media and in the same sequence. The authors are aware that some features about different devices could influence users' experience. For instance, Raptis and colleagues (2013) found an effect of screen size in users' perceived usability and efficacy. The results of their study demonstrated that users are more efficient in seeking information if they interact with screens larger than 4.3 inches and this affects their perception of user experience.

This experiment utilized a desktop pc and a tablet that had both a screen larger than 4.3 inches in order to minimize the effect of screen size. Moreover, our study had an explorative aim and the main goal was to reach useful insights for marketers, comparing the effectiveness of three different solutions regardless of the specific reasons related to the features of the devices. Based on the results in this study, future research should deepen the understanding of the role of these specific features.

In order to assess differences in user experience due to different displays, it may be beneficial to compare separately the webpage shown on a tablet and on a pc screen, and the PDF version shown on a tablet and on a pc screen, overcoming the effects of external variables. User traits too are considered as exogenous variables and excluded from this study.

It would also be useful to corroborate and generalize our findings for testing the long-term memorization of advertisements on different media. In fact, we expect that the memory will diminish over time as Zielske (1982) has shown. It would be interesting to observe the advertising performance over time that different media are able to promote. In this way it could be possible to provide a metric to be used in media-planning (Foucher et al., 2006). 
Further research will consider these aspects to understand more in detail the typical memorization and experience behaviors that characterize each medium.

Certainly, this research contributes to the today's debate on the possibilities that the neuromarketing methodology offers to understand objectively behavioral aspects to which marketing has always paid attention but with limited results. In this sense passive physiologic measures in general have the advantage of not disturbing cognitive processes and for this reason are suitable to analyze this phenomenon so as already years ago Rothschild (1988) indicated. Even recent research has confirmed the validity of these "neuro" methods in providing more direct and detailed information on important aspects of consumer response to marketing messages giving additional insights that lead to better decision-making processes (Stipp, 2015).

\section{REFERENCES}

AAKER, D.A. and D.M. STAYMAN, "Measuring Audience Perceptions of Commercials and Relating Them to Ad Impact." Journal of Advertising Research 30, 4 (1990): 7-17.

AAKER, DAVID S., and D. E. BRUZZONE. "Causes of Irritation in Advertising", Journal of Marketing 49, 2 (1985): 47-57.

ADEMOLA, O.B. "Effects of Gender-Role Orientation, Sex of Advert Presenter and Product Type on Advertising Effectiveness." European Journal of Scientific Research 35, 4 (2009): 537-543.

ALBA, J.W., J. W. HUTCHINSON, and J. G. LYNCH. "Memory and Decision Making." In: Handbook of Consumer Behavior, H. Kassarjian and T. Robertson, NJ: Prentice Hall, 1991.

AMBLER, T., A. IOANNIDES, and S. ROSE. "Brands on the Brain: Neuro-Images of Advertising." Business Strategy Review 11, 3 (2000): 17.

ARES, G., A. GIMÉNEZ, F. BRUZZONE, L. VIDAL, L. ANTÚNEZ, and A. MAICHE. "Consumer visual processing of food labels. Results from an eye-tracking study”, Journal of Sensory Studies 28 (2013): 138-153.

ARNOLD, H.J., and D.C. FELDMAN. "Social Desirability Response Bias in Self-Report Choice Situations." Academy of Management Journal 24, 2 (1981): 377- 385.

BAACK, D.W., R.T. WILSON, and B.D. TILL. "Creativity and Memory Effects: Recall, Recognition, and an Exploration of Nontraditional Media." Journal of Advertising 37, 4 (2008): 8594.

BAEK, T.H., and M. MORIMOTO. "Stay Away From Me: Examining the Determinants of Consumer Avoidance of Personalized Advertising." Journal of Advertising 41, 1 (2012): 59-76.

BARNETT, S.B., and M. CERF. "A Ticket for Your Thoughts: Method for Predicting Content Recall and Sales Using Neural Similarity of Moviegoers." Journal of Consumer Research 44, 1 (2017): 122.

BENWAY, J.P., and D.M. LANE. (1998, December 5). "Banner Blindness: Web Searchers Often Miss Obvious Links", from Internetworking, http://www.internettg.org/newsletter/dec98/banner_ blindness.html.

BETTMAN, J.R. An Information Processing Theory of Consumer Choice. MA: Addison Wesley Publishing Company, Reading, 1979.

BEZJIAN, A. A., B. CALDER, and D. IACOBUCCI. "New Media Interactive Advertising vs. Traditional Advertising." Journal of Advertising Research 38, 4 (1998): 23-32.

BRACKETT, L., and J. B. CARR. "Cyberspace Advertising vs. Other Media: Consumer vs. Mature Student Attitudes." Journal of Advertising Research 41, 5 (2001): 23-32.

CACIOPPO, J.T., L. G. TASSINARY, and G. G. BERNTSON. Handbook of Psychophysiology, 2nd edition. NY: Cambridge University Press, 2000.

CHANDON, P. "Do we Know What WE Look At? An Eye Tracking Study of Visual Attention and Memory for Brands at The Point of Purchase." INSEAD. Fontainebleau, 2002. 
CHRISTIANSON, S. A., E.F. LOFTUS, H. HOFFMAN, and G.R. LOFTUS. "Eye Fixations and Memory for Emotional Events." Journal of Experimental Psychology: Learning, Memory, and Cognition 17 (1991): 693-701.

CICERI A., A. STASI, G. NARDONE, G. SONGA, M. MAURI, and V. RUSSO. "Effect of Information on Food Evaluation and Willingness to Buy. A Study from a Neuromarketing Perspective." Neuromarketing Theory \& Practice 14 (2015).

COWEN, L., L.J. BALL, and J. DELIN. "An Eye-Movement Analysis of Web Page Usability.” In: People and computers XVIII: design for life proceedings of HCI, X. Faulkner J. Finlay, and F. Dètienne, Berlin: Springer-Verlag, 2004.

DAUGHERTY, T., E. HOFFMAN, K. KENNEDY, M. NOLAN, and F. DERICO DE GREGORIO. "Utilizing consumer neuroscience to diagnose advertising effectiveness." American academy of advertising conference proceedings 64 (2012).

DEITZ, G.D., M. B. ROYNE, M. C. PEASLEY, J. C. HUANG, and J. T. COLEMAN. "EEG-Based Measures Versus Panel Ratings: Predicting Social Media-Based Behavioral Response to Super Bowl Ads by World Advertising Research Center." Journal of Advertising Research 56, 2 (2016): 217-227. DEUBEL, H., and W.H. SCHNEIDER. "There is no Expressway to a Comprehensive Theory of The Coordination of Vision, Eye Movements and Visual Attention." Behavioral and Brain Sciences 16 (1993): 575-576.

DIMIGEN, O., W. SOMMER, A. HOHLFELD, A. M. JACOBS, and R. KLIEGL. "Coregistration of Eye Movements and EEG in Natural Reading: Analyses and Review." Journal of Experimental Psychology: General 140, 4 (2011): 552-572.

DMOCHOWSKI, J.P., M. A. BEZDEK, B.P. ABELSON, J. S. JOHNSON, E. H. SCHUMACHER, and L.C. PARRA. "Audience Preferences are Predicted by Temporal Reliability of Neural Processing." Nature Communications 5 (2014): 1-9.

DRĖZE, X., and F. X. HUSSHERR. "Internet Advertising: is Anybody Watching?" Journal of Interactive Marketing 17, 4 (2003): 8-23.

DREZZE, X., and F. ZUFRYDEN. "Internet Advertising: The Medium is The Difference." Consumption, Markets and Culture 4, 1 (2000): 23-37.

DU PLESSIS, E. “Recognition Versus Recall.” Journal of Advertising Research 34, 3 (1994): 7591.

DUBOW, J. S. "Point of View: Recall Revisited: Recall Redux." Journal of Advertising Research 34, 3 (1994): 92-106.

DUNCAN, C. P. and J.E. NELSON, "Effects of Humor in a Radio Advertising Experiment." Journal of Advertising 14, 2 (1985): 33-40.

ELLIOT, M., and P. SPECK. "Consumer Perceptions of Advertising Clutter and its Impact Across Various Media." Journal of Advertising Research 38, 1 (1998): 29-42.

ESFAHANI E. T. and V. SUNDARARAJAN. "Using Brain-Computer Interfaces to Detect Human Satisfaction in Human-Robot Interaction," International Journal of Humanoid Robotics 8, 1 (2011): 87-101.

EVELAND, W.P. and S. DUNWOODY. "User Control and Structural Isomorphism or Disorientation and Cognitive Load? Learning from the Web Versus Print." Communication Research 28, 1 (2001): 48-78.

FENNIS, B.M., and A.B. BAKKER. "Stay Tuned We Will Be Back Right After These Messages: Need to Evaluate Moderates the Transfer of Irritation in Advertising," Journal of Advertising 30, 3 (2001): 15-25.

FOUCHER S., P. LE BLANC, A. MORGENSZTERN and T. VALLAUD. "Un Exemple De Médiaplanning Multimédia." Décisions Marketing 41 (2006): 7-22.

FRIESTAD, M., and E. THORSON. "Remembering Ads: The Effects of Encoding Strategies, Retrieval Cues, and Emotional Response.” Journal of Consumer Psychology 2, 1 (1993): 1-24. 
FURNHAM, A., and L. MAINAUD. "The Effect of French Television Sexual Program Content on The Recall of Sexual and Nonsexual Advertisements." Journal of Sex Research 48, 6 (2011): 590598.

GALLAGHER, K., K.D. FOSTER, and J. PARSONS. "The Medium Is Not the Message: Advertising Effectiveness and Content Evaluation in Print and on the Web." Journal Of Advertising Research 41, 4 (2001): 57-70.

GOLDBERG, B.S., R. A. SOTTILARE, K. W. BRAWNER, and H. K. HOLDEN. "Predicting Learner Engagement During Well-Defined and Ill-Defined Computer-Based Intercultural Interactions." In: ACII 2011, Part I. LNCS, S. D'Mello, A. Graesser, B. Schuller, and J-C. Martin, Heidelberg, Springer, 6974, 2011.

GONZALEZ-SANCHEZ, J., M. E. CHAVEZ-ECHEAGARAY, R. ATKINSON, and W. BURLESON. "An Agent-Based Software Architecture for a Multimodal Emotion Recognition Framework", 9th Working IEEE/IFIP Conference on Software Architecture, (2011): 187-193.

GRANT, S.T., and C. SCHMIDT. "Empirical Evaluation of the Emotiv Epoc Bci Headset for the Detection of Mental Actions." Proceedings of the Human Factors and Ergonomics Society 56th annual meeting, 2012.

GREYSER, S.A. "Irritation in advertising”, Journal Of Advertising Research 13, 1 (1973): 3-10.

GRUSSELL, M. Advertising? "Yes Please, But Only When It's My Choice." Journal of Media Business Studies 4, 3 (2007): 87-101.

HA, L., and K. MCCANN. "An Integrated Model of Advertising Clutter in Offline and Online Media." International Journal of Advertising 27, 4 (2008): 569-592.

HENDERSON J.M., and A. HOLLINGWORTH. "Eye movements and visual memory: Detecting changes to saccade targets in scenes", Perception \& psychophysics 65, 1 (2003): 58-71.

HERVET, G., K. GUÉRARD, S. TREMBLAY, and M. S. CHTOUROU. "Is Banner Blindness Genuine? Eye-Tracking Internet Text Advertising." Applied Cognitive Psychology 25, 5 (2011): 708716.

HIGGINS, E., M. LEINENGER, and K. RAYNER. "Eye Movements When Viewing Advertisements." Frontiers in Psychology 5, 3 (2014): 1-15.

HUMPHREY, K., and G. UNDERWOOD. "Knowledge Moderates the Influence of Visual Saliency in Scene Recognition.” British Journal of Psychology 100 (2009): 377-398.

HYVARINEN, A., J. KARHUNEN, and E. OJA. "Independent component analysis." NJ: John Wiley and Sons Inc (2001).

INVENTADO, P.S., R. LEGASPI, T. D. BUI, and M. SUAREZ. "Predicting Student's Appraisal of Feedback in an Its Using Previous Affective States and Continuous Affect Labels from EEG Data." Proceedings of the 18th International Conference on Computers in Education, 2010.

KATZ, W. A. "Point of View: A Critique of Split-Brain Theory." Journal Of Advertising Research 23, 2 (1983): 63-66.

KELLARIS, J.J., A. D. COX, and D. COX. "The Effect of Background Music on Ad Processing: A Contingency Explanation.” Journal of Marketing 57, 4 (1993): 114-125.

KESSELS, L. T., and R. A. RUITER. "Eye Movement Responses to Health Messages on Cigarettes Packages." BMN Public Health 12, 1 (2012): 352-360.

KHUSHABA, R.N., C. WISE, S. KODAGODA, J. LOUVIERE, B. E. KAHN, and C. TOWNSEND. "Consumer Neuroscience: Assessing the Brain Response to Marketing Stimuli Using Electroencephalogram (EEG) and Eye-Tracking." Expert Systems with Applications 40, 9 (2013): 3803-3812.

KOUTEPOVA, T., Y. LIU Y, X. LAN, and J. JEONG. "Enhancing Video Games in Real Time with Biofeedback Data." ACM SIGGRAPH ASIA 2010 Posters 56, 2010.

KRUGMAN, D.M. R. J. FOX, J. E. FLETCHER, P.M. FISHER, and T.H. ROJAS. "Do Adolescents Attend to Warnings in Cigarette Advertising? An Eye-Tracking Approach." Journal of Advertising Research 34, 6 (1994): 39-52. 
KRUGMAN, H. E. "Why Three Exposures May Be Enough.” Journal of Advertising Research 12, 6 (1972): 11-14.

KUBER, R., and F. WRIGHT. "Augmenting the Instant Messaging Experience Through the Use of Brain-Computer Interface and Gestural Technologies." International Journal of Human-Computer Interaction 29, 3 (2013): 178-191.

LANG, P. J. "The Emotion Probe: Studies of Motivation and Attention." American Psychologist 50, 5 (1995): 372-385.

LANGLEBEN, D. D., J. W. LOUGHEAD, K. RUPAREL, J. G. HAKUN, S. BUSCH-WINOKUR, M. B. HOLLOWAY, A. A. STRASSE, J. N. CAPPELLA, and C. LERMAN. "Reduced Prefrontal and Temporal Processing and Recall of High Sensation Value." NeuroImage 46, 1 (2009): 219-225. LAPA, C. "Using Eye-Tracking to Understand Banner Blindness and Improve Website Design." Rochester Institute of Technology. RIT Digital Media Library, 2007.

LARSEN, J. T., C. J. NORRIS, and J. T. CACIOPPO. "Effects of Positive and Negative Affect on Electromyographic Activity Over Zygomaticus Major and Corrugator Supercilii." Psychophysiology 40, 5 (2003): 776-785.

LAUBROCK, J., R. ENGBERT, M. ROLFS, and R. KLIEGL. "Microsaccades are an Index of Covert Attention: Commentary on Horowitz, Fine, Fencsik, Yurgenson and Wolfe." Psychological Science 18, 4 (2007): 364-366.

LEE, N., BRODERICK, L., and L. CHAMBERLAIN. "What is "Neuromarketing"? A Discussion and Agenda for Future Research." International Journal of Psychophysiology 63,2 (2006): 200-204. LIAO, L.X., A. M. CORSI, P. CHRYSOCHOU, and L. LOCKSHIN. "Emotional Responses Towards Food Packaging: A Joint Application of Self-Report and Physiological Measures of Emotion." Food Quality and Preference, 42 (2015): 48-55.

LIEVESLEY, R., M. WOZENCROFT, and D. EWINS. "The Emotiv EPOC Neuroheadset: an Inexpensive Method of Controlling Assistive Technologies Using Facial Expressions and Thoughts?" Journal of Assistive Technologies 5, (2011): 67-82.

LODISH, L. M., M. ABRAHAM, S. KALMENSON, J. LIVELSBERGER, B. LUBETKIN, B. RICHARDSON and M. E. STEVENS. "How T.V. Advertising Works: a Meta-Analysis of 389 Real World Split Cable T.V. Experiments." Journal of Marketing Research 32, 2 (1995): 125-39.

LOFTUS, G. R. "Eye Fixations and Recognition Memory for Pictures." Cognitive Psychology 3, (1972): 525-551.

LOHSE, G. L. "Consumer Eye Movement Patterns on Yellow Pages Advertising." Journal of Advertising 26, 1 (1997): 61-73.

MATTILA, A. S. "Do Emotional Appeals Work for Services?" International Journal of Service Industry Management 10, 3 (1999): 292-306.

MAURI, M., F. ONORATI, and V. RUSSO. "Psychophysiological Assessment of Emotions." International Journal of Bioelectromagnetism 14, 3 (2012): 133-140.

MCCOY S., A. EVERARD, P. POLAK, and D.F. GALLETTA. "The effects of online advertising" Communications Of The Acm, 50, 3 (2007).

MCLUHAN, M. "Understanding Media: The Extensions of Man.” NY: McGraw Hill, 1964.

MEHTA, A., and S. PURVIS. "Reconsidering Recall and Emotion in Advertising." Journal of Advertising Research 46 (2006): 49-56.

MEYERS-LEVY, J., and P. MALAVIYA. "Consumers' Processing of Persuasive Advertisements: an Integrative Framework of Persuasion Theories." Journal of Marketing 63, 4 (1999): 45- 60.

MISSAGLIA, A.L., A. OPPO, M. MAURI, B. GHIRINGHELLI, A. CICERI, and V. RUSSO. "The Impact of Emotions on Recall: An Empirical Study on Social Ads." Journal of Consumer Behaviour 16, 5 (2017): 1-10

NAGAR, K. "Advertising Effectiveness in Different Media: A Comparison of Web and Television Advertising." IIMB Management Review (Indian Institute Of Management Bangalore), 21, 3 (2009): 245-260. 
NEDUNGADI, A., A. MITCHELL, and I. E. BERGER. "A Framework for Understanding the Effects of Advertising Exposure on Choice." In: Advertising Exposure, Memory, and Choice. A. Mitchell, 89-116, NJ: Erlbaum Associates: Hillsdale, 1993.

O'CONNELL, B., S. WALDEN, and A. POHLMANN. "Marketing and Neuroscience. What Drives Customer Decisions?.” American Marketing Association, White Paper, 2011.

OBERMILLER, C., and E.R. SPANGENBERG. "Development of a Scale to Measure Consumer Skepticism Toward Advertising," Journal of Consumer Psychology 7 2, (1998): 159-186.

OHME, R., D. REYKOWSKA, D. WIENER, and A. CHOROMANSKA. "Analysis of Neurophysiological Reactions to Advertising Stimuli by Means of EEG and Galvanic Skin Response Measures." Journal of Neuroscience, Psychology, and Economics 2, 1 (2009): 21-31.

ORZAN, G., I.A. ZARA, and V.L. PURCAREA. "Neuromarketing techniques in pharmaceutical drugs advertising. A discussion and agenda for future research." Journal Of Medicine \& Life 5, 4 (2012): 428-432.

PERFECT, T. J., and C. ASKEW. "Print Adverts: not Remembered but Memorable." Applied Cognitive Psychology 8 (1994): 693-703.

PIETERS, R. and L. WARLOP. "Visual Attention During Brand Choice: the Impact of Time Pressure and Task Motivation." International Journal of Research Marketing 16, 1 (1999): 1-16.

PIETERS, R., L. WARLOP, and M. WEDEL. "The Influence of Advertisement Familiarity and Originality on Visual Attention and Brand Memory." Research Report 9953, Katholieke Universiteit Leuven, 1999.

PLASSMANN, H., T. Z. RAMSØY, and M. MILOSAVLJEVIC. "Branding The Brain: a Critical Review and Outlook." Journal of Consumer Psychology 22, 1 (2012): 18-36.

POELS, K., and S. DEWITTE. "How to Capture the Heart? Reviewing 20 Years of Emotion Measurement in Advertising." Journal of Advertising Research 46, 1 (2006): 18-37.

PRYOR, J.B., F. X. GIBBONS, R. A. WICKLUND, R. H. FAZIO, R. HOOD. "Self-Focused Attention and Self-Report Validity." Journal of Personality 45, 4 (1977): 513-527.

RAINVILLE, P., A. BECHARA, N. NAQVI, and A. R. DAMASIO. "Basic Emotions are Associated with Distinct Patterns of Cardiorespiratory Activity." International Journal of Psychophysiology 61, 1 (2006): 5-18.

RAPTIS, D., N. TSELIOS, J. KJELDSKOV, and M. B. SKOV. "Does Size Matters? Investigating the Impact of Mobile Phone Screen Size on Users' Perceived Usability, Effectiveness and Efficiency." Proceedings of MobileHCI 2013. ACM Press, New York, (2013): 127-136.

RAYNER, K. "Eye Movements in Reading and Information Processing: 20 Years of Research." Psychological Bulletin 124, 3 (1998): 372-422.

REED, M. "Going beyond the banner ad." Marketing (1999): 25-26.

RIZZOLATTI, G., L. RIGGIO, and B. M. SHELIGA. "Space and Selective Attention.” In: Attention and Performance XV. C. Umiltà and M. Moscovitch Eds. MIT Press, (1994).

ROSBERGEN, E., R. PIETERS, and M. WEDEL. "Visual attention to advertising: A segment-level analysis." Journal of Consumer Research 24 (1997): 305-314.

ROTHSCHILD, M. L., Y.J. HYUN, B. REEVES, E. THORSON, and R. GOLDSTEIN. Hemispherically Lateralized EEG as a Response to Television Commercials. Journal Of Consumer Research 15, 2 (1988): 185-198.

ROTHSCHILD, M.L. "Electroencephalic (Brain Wave) Data as a Commercial Diagnostic," Madison: University of Wisconsin (1982), unpublished paper.

RUSSO, J. E. "Eye Fixations Can Save The World: a Critical Evaluation and a Comparison Between Eye Fixations and Other Information Processing Methodologies." In: Advances in Consumer Research Vol.5. K. Hunt and A. Abor. MI Association for Consumer Research, 1978.

RUSSO, V. "Neuromarketing, Comunicazione e Comportamenti di Consumo." Milano: Franco Angeli, 2015.

SCOTT, N., C. GREEN, S. FAIRLEY. "Investigation of the Use of Eye Tracking to Examine Tourism Advertising Effectiveness." Current Issues in Tourism 19, 7 (2015): 1-9. 
SENTINEL, O. “Tablet Advertising Drives Purchases.” Center For Media Research; OPA; Frank Magid Associates, 2012.

SIMOLA, J., M. KIVIKANGAS, J. KUISMA, and C. M. KRAUSE. "Attention and Memory for Newspaper Advertisements: Effects of Ad-Editorial Congruency and Location." Applied Cognitive Psychology 27, 4 (2013): 429-442.

SPECK, P.S., and M.T. ELLIOTT. "Predictors Of Advertising Avoidance in Print And Broadcast Media," Journal of Advertising 26, 3, (1997): 61-76.

STAFFORD, M.R., F. T. STAFFORD, and E. DAY. "A Contingency Approach: the Effects of Spokesperson Type and Service Type on Service Advertising Perceptions." Journal of Advertising 31, 2 (2002): 17-34.

STIPP, H. "The Evolution of Neuromarketing Research: From Novelty to Mainstream." Journal Of Advertising Research 55, 2 (2015): 120-122.

SUNDAR, S.S., S. NARAYAN, R. OBREGON, R. and C. UPPAL. "Does Web Advertising Work? Memory for Print vs. On Line Media." Journalism \& Mass Communication Quarterly 75, 4 (1998): $822-835$.

TATLER, B. W., I.D. GILCHRIST, and M.F. LAND. "Visual memory for objects in natural scenes: from fixations to object files." Quarterly Journal of Experimental Psychology. A, Human Experimental Psychology 58, 5 (2005): 931-960.

TEWKSBURY, D., and S. ALTHAUS. "Differences in Knowledge Acquisition Among Readers of the Paper and Online Versions of a National Newspaper." Journalism \& Mass Communication Quarterly 77, 3 (2000): 457-479.

THORSON, E., and X. ZHAO. "Television Viewing Behavior as an Indicator of Commercial Effectiveness." In: Measuring Advertising Effectiveness. W.D. Wells, Lawrence Erlbaum Assoc, (1997): 221-237.

TILL, B.D., and D. W. BAACK. "Recall and Persuasion: Does Creative Advertising Matter?." Journal of Advertising 34, 3 (2005): 47-57.

TILL, B.D., and M. BUSLER. "Matching Products With Endorsers: Attractiveness Versus Expertise." Journal of Consumer Marketing 15, 6 (1998): 576-586.

VARAN, D., J. MURPHY, C. F. HOFACKER, J. A. ROBINSON, R. F. POTTER, and S. BELLMAN. "What Works Best When Combining Television Sets, PCs, Tablets, or Mobile Phones? How Synergies Across Devices Result From Cross-Device Effects and Cross-Format Synergies", Journal of Advertising Research 53, 2 (2013): 212-220.

VECCHIATO, G., A.G. MAGLIONE, P. CHERUBINO, B. WASIKOWSKA, A. WAWRZYNIAK, A. LATUSZYNSKA, M. LATUSZYNSKA, K. NERMEND, I. GRAZIANI, M.R. LEUCCI, A. TRETTEL A, and F. BABILONI. "Neurophysiological Tools to Investigate Consumer's Gender Differences During the Observation of TV Commercials", Computational and Mathematical Methods in Medicine, (2014): 1-12.

VECCHIATO, G., L. ASTOLFI, F. DE VICO FAllani, F. CinCOTTI, D. MATTIA, S. SALINARI R. SORANZO, and F. BABILONI. "Changes in Brain Activity During the Observation of TV Commercials by Using EEG, GSR and HR Measurements." Brain Topography 23, 2 (2010): $165-179$.

VENKATRAMAN, V., DIMOKA, A., PAVLOU, P. A., KHOI, V., HAMPTON, W., BOLLINGER, B., and R.S. WINER. "Predicting Advertising Success Beyond Traditional Measures: New Insights from Neurophysiological Methods and Market Response Modeling." Journal Of Marketing Research 52, 4 (2015): 436-452.

VENKATRAMAN, V., J. A. CLITHERO, G.J. FITZSIMONS, and S. A. HUETTEL. "New Scanner Data for Brand Marketers: How Neuroscience can Help Better Understand Differences in Brand Preferences." Journal of Consumer Psychology 22, 1 (2012): 143-153.

WAWRZYNIAK, A., and B. WASIKOWSKA. "Neuroscience techniques in studying advertisements effectiveness: an experimental investigation." Neuropsychoeconomics Conference Proceedings 21 (2016). 
WEDEL, M., and R. PIETERS. "Eye Fixations on Advertisements and Memory for Brands: a Model and Findings." Marketing Science 19, 4 (2000): 297-312.

WELLS, W. D., C. LEAVITT, and M. MCCONVILLE, "A Reaction Profile for TV Commercials," Journal of Advertising Research 11, 6 (1971): 11-17.

ZIELSKE, H.A. "Does Day-After Recall Penalize 'Feeling' Ads?" Journal of Advertising Research 22, 1 (1982): 19-22. 